\title{
CAMBIASSU

\section{0 feminicídio na capa da Folha de S. Paula. considerações sobre a cobertura do jornal paulistano entre 2015 e 2019}

The feminicide on the cover of Folha de $S$. Paula. considerations about the coverage by the São Paulo newspaper between 2015 and 2019

Bárbara Maria Santos de Lima

Mestranda em Comunicação pela Universidade Anhembi Morumbi, com bolsa CAPES. Possui graduação em Comunicação social - Jornalismo pela Universidade Anhembi Morumbi (2020), onde realizou pesquisa de Iniciação Científica. É pesquisadora do Grupo de Pesquisa Representações, Mediações e Humor na Cultura Audiovisual (UAM/CNPq). E-mail: bmbarbaralimaOrgmail.com.

\section{Nara Lya Cabral Scabin}

Professora do Programa de Pós-Graduação em Comunicação da Universidade Anhembi Morumbi. Doutora e mestre em Ciências da Comunicação pela Universidade de São Paulo e bacharel em Comunicação Social com Habilitação em Jornalismo pela mesma instituição. Líder do Grupo de Pesquisa Representações, Mediações e Humor na Cultura Audiovisual (UAM/CNPq). E-mail: naralyacabral@yahoo.com.br. 


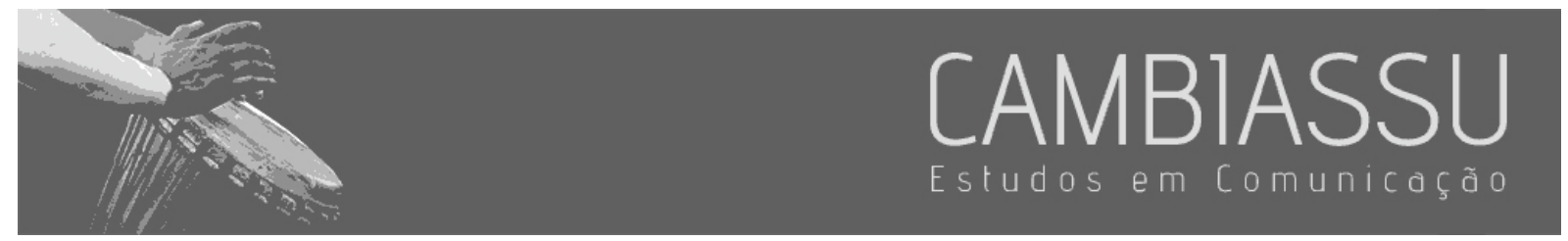

\section{Resumo}

Diante dos altos índices de feminicídio no Brasil e considerando a relevância do jornalismo como instrumento de conscientização da sociedade sobre a violência de gênero, a presente pesquisa buscou mapear a presença de matérias de capa sobre o crime em foco na Folha de S. Paulo, entre 2015 e 2019. Os levantamentos realizados junto ao acervo digitalizado do jornal apontaram a concessão de baixa visibilidade a casos e à temática do feminicídio em sua primeira página. Assim, as conclusões do estudo chamam a atenção para a existência de silêncios constitutivos do discurso do jornal, bem como para a conexão dos enunciados jornalísticos em relação a discursos em circulação no espaço público.

Paldvras-chave: Feminicídio. Folha de S. Paulo. Gênero.

Discursos circulantes.

\section{Abstract}

Given the high rates of feminicide in Brazil and considering the relevance of journalism as an instrument to raise society's awareness of gender violence, this research intended to map the presence of stories about the focused crime in the cover of Folha de S. Paulonewspaper between 2015 and 2019. The trackings showed a low visibility conferred by the vehicle to feminicide cases and theme on its front page. Thus, the study conclusions draw attention to constitutive silences of the newspaper discourse, as well as they point out connections between the journalistic enunciates and circulating discourses in the public space.

Keywords: Feminicide. Folha de S. Paulo. Gender. Circulating discourses. 


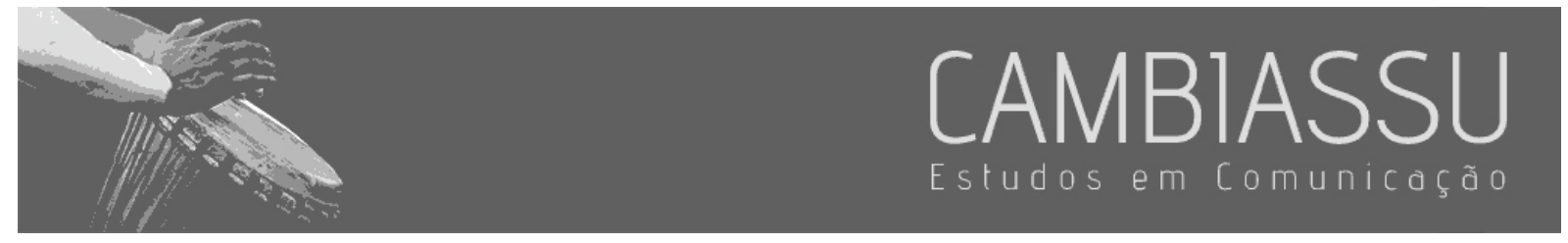

\section{1 lntrodução}

Em 2019, 1.314 mulheres foram vítimas de feminicídio: isto é, foram assassinadas devido à sua condição de gênero. Já no ano seguinte, quando a lei que tipificou o crime de feminicídio no Brasil completou cinco anos, o aumento de casos cresceu $22,2 \%$ em relação a março e abril de 2019 , segundo reportagem disponível no portal G1 (FANTÁSTICO, 2020, on-line).

Para que esses casos fossem registrados separadamente de homicídios comuns, o crime de feminicídio precisou ser tipificado pela lei $n^{0} 13.104 / 15$, sancionada em 2015 , no governo da então presidente Dilma Rousseff. Considerando sua definição conforme o texto da Lei, o feminicídio pode ser compreendido como:

[...] um crime de ódio. O conceito surgiu na década de 1970 com o fim de reconhecer e dar visibilidade à discriminação, opressão, desigualdade e violência sistemática contra as mulheres, que, em sua forma mais aguda, culmina na morte. Essa forma de assassinato não constitui um evento isolado e nem repentino ou inesperado; ao contrário, faz parte de um processo contínuo de violências, cujas raízes misóginas caracterizam. Trata-se de um crime de ódio. O conceito surgiu na década de 1970 com o fim de reconhecer e dar visibilidade à discriminação, opressão, desigualdade e violência sistemática contra as mulheres, que, em sua forma mais aguda, culmina na morte. (MENICUCCI, 2019, on-line).

Trata-se, portanto, como já apontado, do crime cometido contra a mulher em decorrência de sua condição de gênero. A ação criminosa implica em pena de reclusão de 12 a 30 anos, o que corresponde a um aumento de $1 / 3$ do tempo de pena em relação ao homicídio comum. Isso porque, graças à assim chamada Lei do Feminicídio, o assassinato de mulheres em virtude de sua condição de gênero foi transformado em crime hediondo (delitos de riscos que requerem uma atenção maior do Estado), representando um agravante para o crime de homicídio. Um dos primeiros casos de feminicídio a ser registrado no Brasil ocorreu em 12 de abril de 2015, quando Márcia Maria, de 44 anos, foi morta a tiros em Itupeva, interior de São Paulo (BARBOSA; MEIRELLES; MENEZES, 2020). 


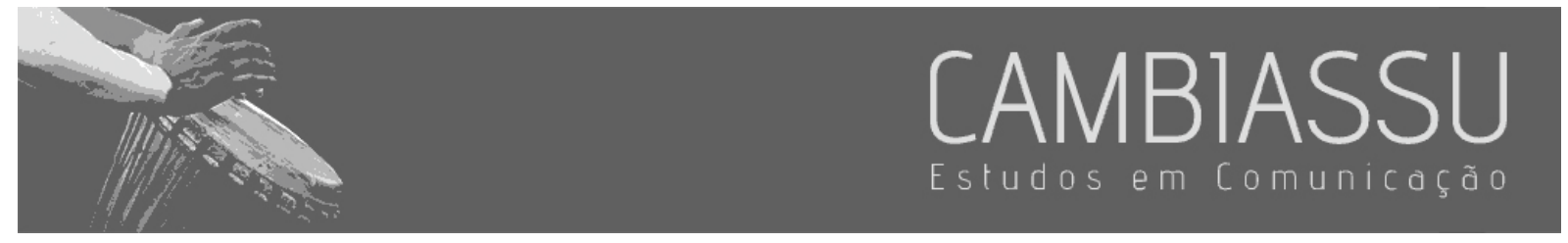

Outro dado que deve ser observado é que a lei 13.104/15 abrange mulheres cis e transexuais, ainda que a palavra "gênero" tenha sido banida do contexto escrito da lei, por pressão de grupos religiosos e conservadores; na ocasião de sua votação no Congresso, o então deputado Eduardo Cunha declarou que retiraria o projeto de pauta caso dentro do descritivo da lei ocorresse o uso da palavra "gênero" (FLORES, 2017).

Cinco anos após sua promulgação, são muitos os obstáculos que a aplicação da lei ainda enfrenta, como a resistência entre parte da opinião pública em reconhecer a especificidade do crime de feminicídio frente a outras formas de homicídio. Não obstante, dar visibilidade a esse tipo de crime, favorecendo a conscientização da sociedade a respeito da violência de gênero, é um dos principais impactos decorrentes da criação desse instrumento legal.

Nesse sentido, um importante aliado na promoção dos direitos da mulher e sensibilização a respeito do feminicídio, em uma sociedade democrática, deve ser a imprensa. Dessa forma, o presente artigo apresenta resultados de uma pesquisa que buscou investigar a cobertura realizada pelo veículo jornalístico paulistano Folha de S. Paulo - um dos maiores jornais em circulação e tiragem do país e o maior de São Paulo1 - sobre casos de feminicídio no Brasil.

A opção por priorizar o veículo em questão como foco de nossa investigação se dá pelo fato de a Folha ser representativa do chamado "jornalismo de referência", termo que diz respeito a uma esfera do campo jornalístico que materializa aspectos como tradição, prestígio e credibilidade. O jornalismo de referência também pode ser caracterizado por possuir expressivos índices de tiragem e circulação, pela ênfase conferida a temas de política, economia e assuntos internacionais e pelo fato

\footnotetext{
1 Quando somadas suas tiragens impressas e digitais, a Folha de S. Paulo lidera o ranking dos jornais diários tradicionais paulistas, com média de 343.522 exemplares em dezembro de 2020, mantendo a posição de liderança verificada em dezembro de 2018, segundo dados do Instituto Verificador de Circulação (IVC). Quando comparada aos grandes jornais diários tradicionais do restante do país, a Folha perdia em número total de assinaturas somente para O Globo em dezembro de 2018; já em dezembro de 2020, o diário paulista ultrapassa o concorrente carioca por pouco menos de dois mil exemplares diários (YAHIA, 2021, online).
} 


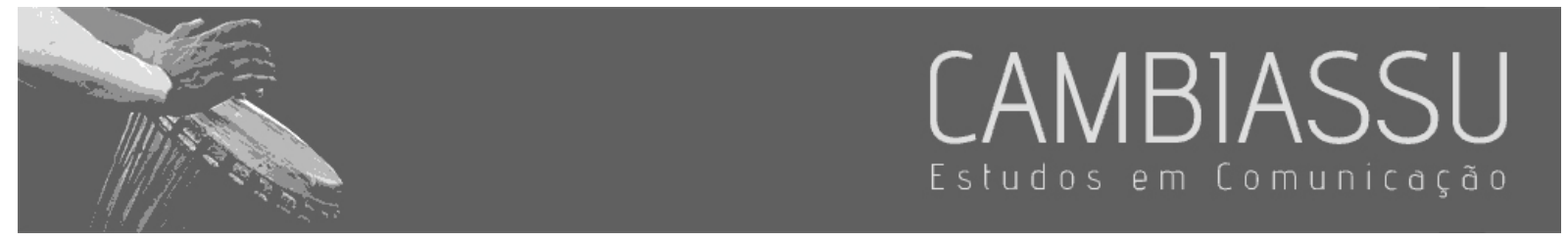

de se dirigir, enquanto público ideal, a um leitor competente do mundo social (as elites econômica e cultural) (ZAMIN, 2014).

Em relação ao corpus analisado, este abarca todas as matérias jornalísticas publicadas na capa da Folha de S. Paulo entre 9 de março de 2015 e 31 de dezembro de 2019 que empregam a expressão "feminicídio". Para tanto, os levantamentos foram realizados junto ao acervo digitalizado da Folha disponível on-line, tendo sido utilizado o mecanismo de busca da própria plataforma por meio de filtros de palavra-chave e período de consulta. A palavra-chave pesquisada foi "feminicídio", e o período de observação adotado no trabalho abarca o intervalo compreendido entre o dia em que a Lei 13.104/15 entrou em vigor no Brasil e o momento imediatamente anterior ao início da presente pesquisa.

Para as análises, foi adotada uma tabela que classifica as matérias coletadas por meio de data, trecho em que a palavra-chave em foco aparece ("feminicídio"), classificação da matéria em função de gênero discursivo², editoria em que o texto foi publicado e autoria.

\section{Discursos circulantes, jornalismo e gênero}

Um conceito-chave à problemática em foco nesta pesquisa é o de "discurso circulante", conforme proposto por Patrick Charaudeau (2010). Segundo o autor, é do amálgama de discursos em circulação que emergem posições preponderantes no espaço público, as quais costumamos identificar como "opinião pública"; da mesma forma, é da identificação com discursos em circulação que se formam posicionamentos assumidos no debate público por diferentes atores sociais.

Além disso, é da natureza dos discursos circulantes abarcarem enunciados de natureza sintetizadora e simplificadora sobre as coisas do mundo, terreno fértil para a propagação de preconceitos e prejulgamentos característicos do domínio do senso comum. Isso porque, como explica

\footnotetext{
2 Optamos por adotar a classificação proposta por Chaparro (2008), que identifica dois gêneros jornalísticos fundamentais: o gênero "relato", que abarca textos de natureza narrativa, tais como notas, notícias e reportagens; e o gênero "comentário", que abrange textos de caráter argumentativo, tais como artigos de opinião e editoriais.
} 


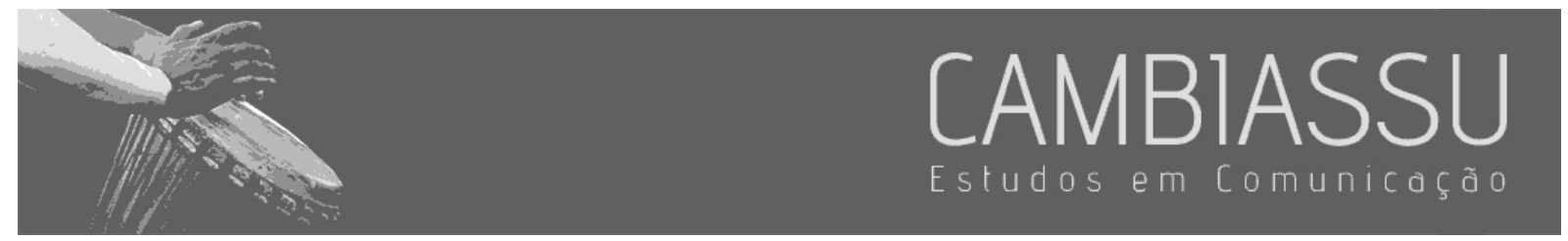

Charaudeau (2010): "o discurso circulante é uma soma empírica de enunciados com visada definicional sobre o que são os seres, as ações, os acontecimentos, suas características, seus comportamentos e os julgamentos a eles ligados" (CHARAUDEAU, 2010, p. 116).

No caso de nosso objeto de estudo, é notável que o feminicídio, embora tenha sido tipificado e visibilizado pela Lei 13.104/15, ainda encontra, em discursos em circulação na sociedade brasileira, focos de naturalização e/ou minimização. Isso fica evidente em casos de descredibilização de mulheres que sofrem agressões ou vivenciam relacionamentos com histórico abusivo ${ }^{3}$. Ao mesmo tempo, é notório que a cobertura jornalística sobre questões de gênero, incluindo aquela sobre violência contra a mulher, possui impacto sobre a cristalização de valores e sentidos e a regulação de práticas sociais.

Não se trata, então, de abordar a violência contra a Mulher - assim com maiúscula, representação de uma essência inerente a todas as mulheres -, nem de analisar as diferentes histórias de violência de mulheres. $O$ foco constrói mulheres e homens quando narra a violência. (GOMES, 2009, p. 2)

A citação de Gomes (2009), anterior à promulgação da Lei do Feminicídio, chama a atenção para a presença de concepções sobre papéis de gênero em discursos sociais, como destaque para discursos midiáticos, evidenciando como os veículos de comunicação, enquanto dispositivos que articulam formas de saber e poder, constroem identidades e determinam subjetividades possíveis para os indivíduos, interpelando-os a ocuparem os "lugares" socioculturais que lhes são destinados.

Em outras palavras, pode-se pensar a imprensa como espaço de concretização de uma "tecnologia de gênero". Isso porque, como aponta Teresa de Lauretis (2019), o gênero - como representação e autorrepresentação - pode ser compreendido como produto de tecnologias sociais,

\footnotetext{
${ }^{3}$ Esse tipo de posicionamento fica evidente quando consideramos as repercussões a casos que recebem projeção midiática, como, por exemplo, a traição seguida de separação do casal de influenciadores digitais Mayra Cardi e o ator Arthur Aguiar. Nesse caso, um post do Jornalista Hugo Gloss no Twitter que noticiava a possível volta do casal trouxe à tona comentários de cunho machista, tais como: "Cansei de mulher fraca que quer dar uma de guerreira, mas depois mostra o quão covarde é. É preciso ser uma idiota para perdoar esse tarado, mas cada uma tem o que merece. Da próxima vez, não se queixe”. Outro comentário ainda dizia: "não sou obrigada a ter empatia, né? Nunca gostei dessa mulher, mas quando aconteceu toda aquela treta fiquei do lado dela, defendi, mas agora vejo que eu devia ter seguido meu instinto de não gostar dela".
} 


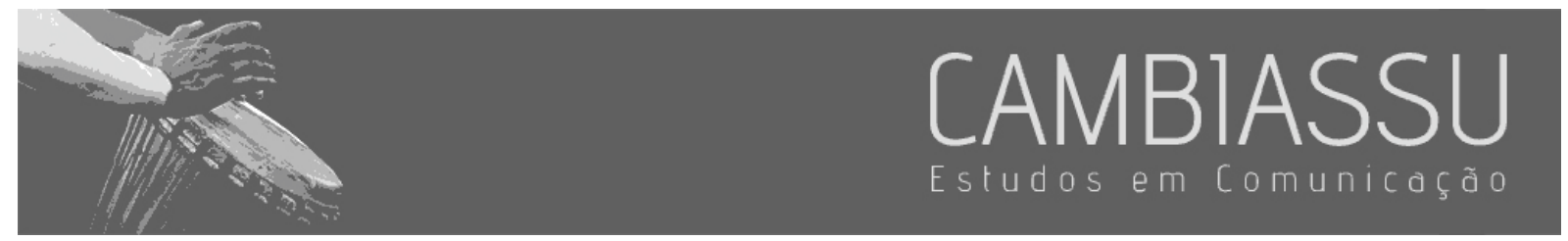

como as mídias, e de "[...] discursos, epistemologias e práticas sociais institucionalizadas, bem como das práticas da vida cotidiana" (LAURETIS, 2019, p. 123).

No caso da Folha de S. Paulo, apesar de seu pertencimento a uma parcela tradicional do campo jornalístico, verifica-se um empenho em publicizar iniciativas, ao longo dos últimos anos, que sinalizam uma aproximação em relação a determinadas perspectivas emergentes na sociedade. Entre estas perspectivas, destaca-se a ampliação da visibilidade adquirida por discursos feministas no século XXI, "momento da consolidação do feminismo decolonial, da teoria queer, do pós-feminismo, dos estudos transgênero" (HOLLANDA, 2019, p. 17). Assim, embora muitas vezes alinhando-se a uma forma difusa de feminismo (PINTO, 2003) própria dos feminismos midiáticos, o jornalismo de referência tem se mostrado atento à crescente visibilidade adquirida por tais demandas no espaço público.

Em 2019, por exemplo, a Folha criou uma editoria de Diversidade, pouco tempo após nomear a jornalista Paula Cesarino Costa como ombudsman. Seu mandato se estendeu entre 2016 a 2019, período em que teceu diversas críticas à atuação do jornal sob uma perspectiva de gênero. Como ela mesma afirmou, em um de seus textos, à época: "Tenho a impressão de que a Folha não parece antenada, empenhada e mobilizada para entender quão necessárias e relevantes são as investigações que desnudem a violência de gênero" (COSTA, 2018, on-line).

Em seu mandato como ombudsman, Costa também denunciou a emergência, em matérias do jornal, de discursos circulantes de cunho machista, a exemplo de posicionamentos atrelados à culpabilização da vítima mulher em casos de estupro, assédio e outros crimes. Isso ocorreu quando a jornalista questionou uma matéria que, ao noticiar o assassinato de uma policial, destacava que a vítima estava em "momentos com bebida, pegação e dança", abrindo espaço a uma possível naturalização ou legitimação da violência a ela infringida (COSTA, 2018).

Outro caso em que a ombudsman se posicionou a partir de uma perspectiva de gênero se deu em 2017, quando ela chamou a atenção para a falta de diversidade no concurso de ilustração do jornal 


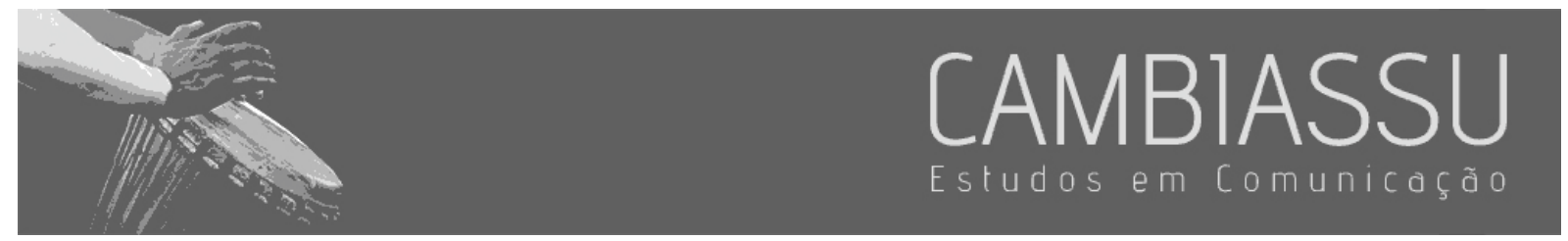

daquele ano, no qual nenhuma mulher havia ficado entre os finalistas, apesar do número expressivo de inscrições. Costa também criticou os baixos índices de mulheres colunistas no jornal - em 2016, por exemplo, havia 130 colunistas ao todo, dos quais somente 32 eram mulheres.

\section{A baixa visibilidade do feminicídio nas capas da folha de s.paulo}

$\mathrm{Na}$ etapa de construção do corpus de análise examinado na pesquisa cujos resultados são apresentados no presente artigo, foram localizadas, ao todo, apenas sete matérias destacadas na capa da Folha de S. Paulo, ao longo dos cinco anos que constituem o período de observação considerado.

Entre os textos localizados, estão três notícias, assim intituladas: "SP registra 1 caso de feminicídio a cada 4 dias" (23/08/2017); "Atual ou ex cometem $71 \%$ de feminicídios e tentativas" (08/03/2019); e "Em 4 dias, 4 mulheres são mortas por conhecidos em SP" (26/11/2019). O corpus também abarca dois artigos de opinião - "Um outro final" (15/08/2018) e "2019, o ano das mulheres no front" (30/12/2019) -, além de uma nota - "Dilma participa da cerimônia sobre a Lei do Feminicídio, no Planalto" (10/03/2015) - e um editorial intitulado "Mulheres sob ataque" (09/03/2019).

De partida, os achados apontam uma sintomática baixa visibilidade do tema em foco nas capas da Folha. Além disso, chama a atenção o fato de que todas as notícias localizadas foram publicadas no caderno de Cotidiano, o que sugere que os casos foram tratados, editorialmente, conforme enfoques e abordagens comuns em outras pautas de violência e polícia. Os demais textos localizados na pesquisa - artigos de opinião e um editorial - foram publicados em espaços de opinião de jornal. Destaca-se, ainda, o fato de nenhuma pauta propositiva de abordagens mais aprofundadas e/ou contextualizadoras sobre feminicídio, como poderíamos encontrar em editorias de Cultura e/ou Política, ter sido destacada na capa do jornal.

Nesse sentido, na data em que a Lei do Feminicídio entrou em vigor, ainda que a tipificação do crime tenha sido um grande marco para as lutas feministas e como garantia de direitos para as 


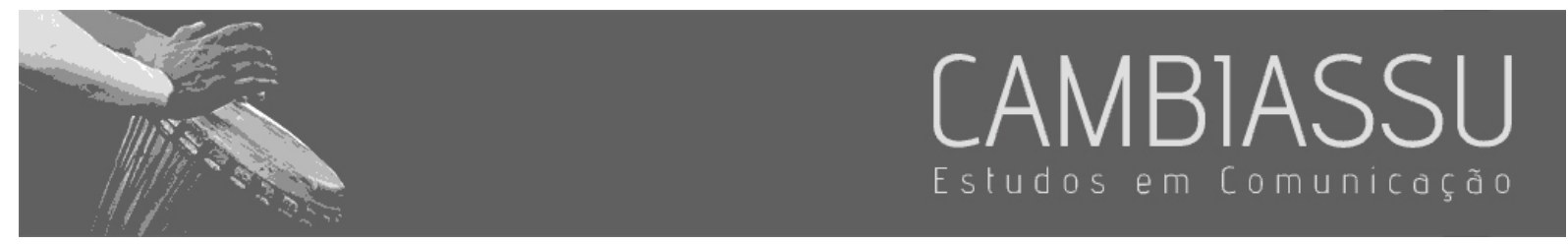

mulheres brasileiras, a Folha de S. Paulo publicou, em sua capa, apenas uma pequena nota de 69 caracteres, o que evidencia a visibilidade relativamente baixa conferida pelo jornal ao assunto na época, como mostram as Figuras 1 e 2 a seguir.

Figura 1 - À esquerda, nota sobre feminicídio na capa da Folha de 10 de março de 2015
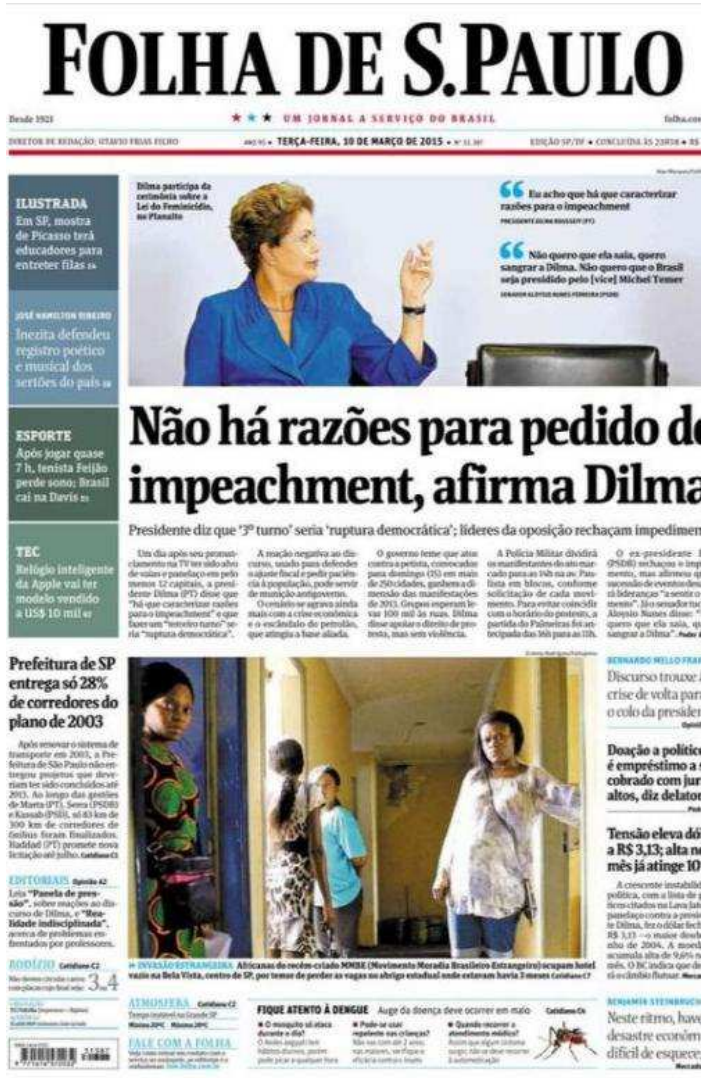

Fonte: Captura de tela realizada pelas autoras/Folha de S. Paulo (2015).

Figura 2 - Detalhe da nota publicada na capa da Folha em 10 de março de 2015 

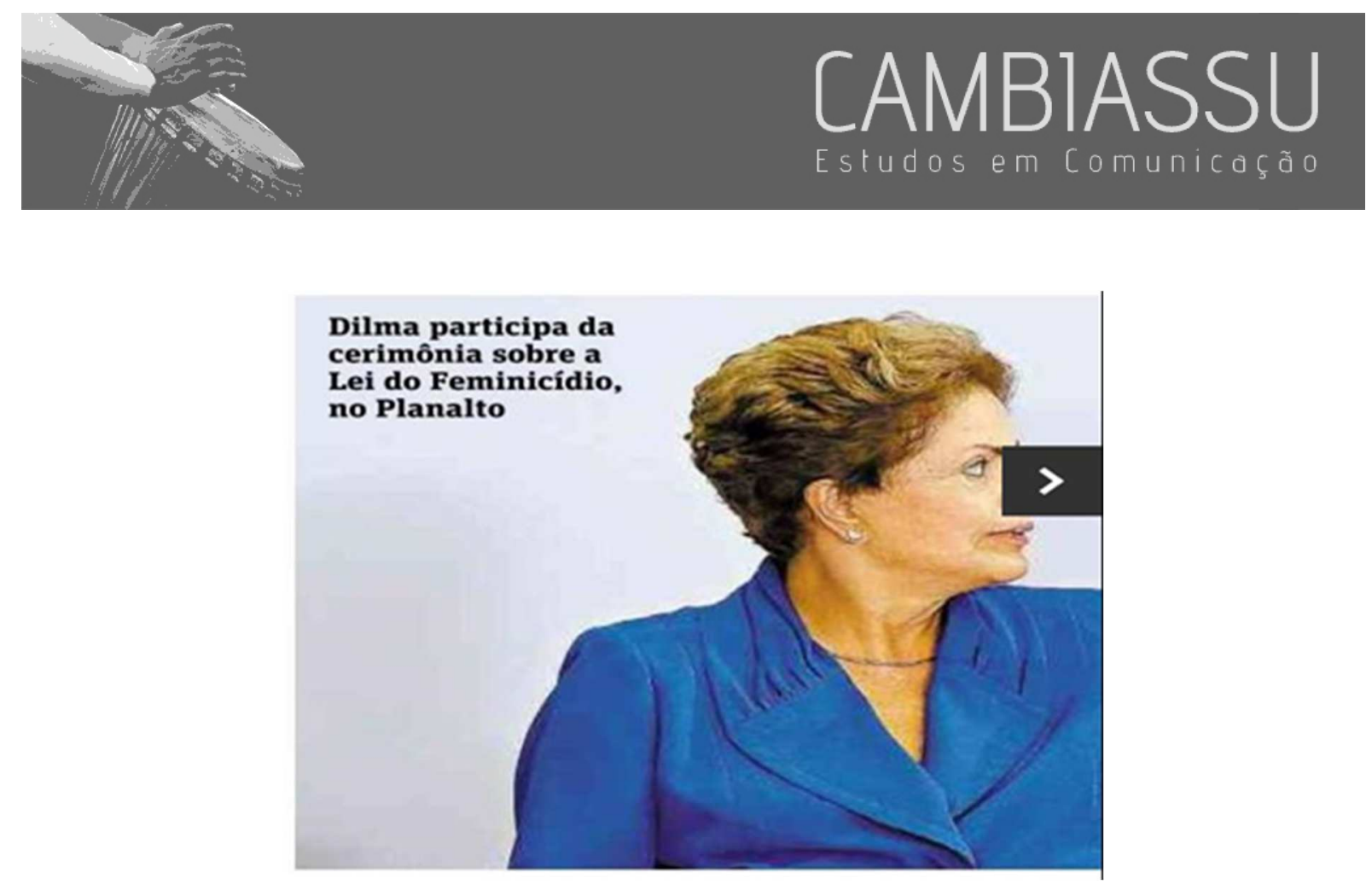

Fonte: Captura de tela realizada pelas autoras/Folha de S. Paulo (2015).

Como se vê, o maior destaque conferido pelo jornal na capa da edição de 10 de março de 2015 diz respeito às movimentações relacionadas ao processo de impeachment da então presidente brasileira Dilma Rousseff. Com efeito, a promulgação da Lei do Feminicídio, que entrava em vigor na mesma data, ganhou espaço mínimo na primeira página do diário paulistano. Tendência similar é identificada na capa da edição de 23 de agosto de 2017: a chamada da matéria "SP registra 1 caso de feminicídio a cada quatro dias", contando com o título, ocupou apenas 11 linhas na capa - enquanto, na mesma edição, a matéria intitulada "Governo planeja limites para novos sócios da Eletrobrás" utiliza o dobro de espaço na capa do jornal. Reforça-se, portanto, a priorização de pautas relacionadas ao campo da política institucional, sobretudo quando relacionadas a ações do Poder Executivo, em detrimento das discussões relativas à Lei do Feminicídio ou à incidência de casos de feminicídio no país ou em regiões e cidades brasileiras.

Já em 8 de março de 2019, a matéria "Atual ou ex cometem 71\% de feminicídios e tentativas" ganhou relativo destaque na capa da Folha, ocupando o topo da primeira página do jornal, ênfase provavelmente devida ao fato de a notícia ter sido publicada no Dia Internacional da Mulher. Este caso difere da capa de 26 de novembro de 2019, de oito meses mais tarde, na qual a chamada para a 


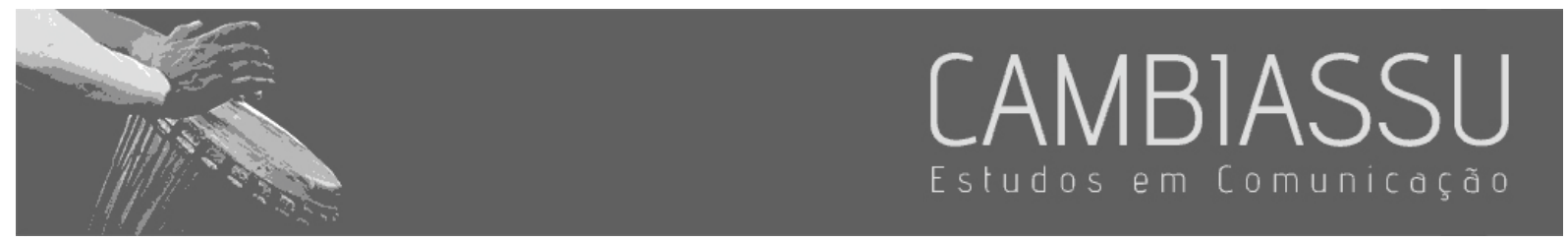

matéria "Em 4 dias, 4 mulheres são mortas por conhecidos em SP" recebeu pequeno destaque, perdendo espaço para a notícia "Campanha de Bolsonaro foi mais cara que o declarado".

Nas imagens a seguir, é possível visualizar a diferença do destaque conferido pela Folha às duas matérias em questão sobre feminicídio publicadas em 2019: na Figura 3, temos a capa publicada no Dia Internacional da Mulher; na Figura 4, é possível perceber a ênfase relativamente menor concedida a uma notícia de teor similar, mas veiculada fora da data comemorativa.

Figura 3 - Ao centro, matéria destacada na capa da Folha de 8 de março de 2019

\section{FOLHA DE S.PAULO}

DESDE $1921 \star \star \star \star$ UM IOHNAL A SERVICO DO BRASIL

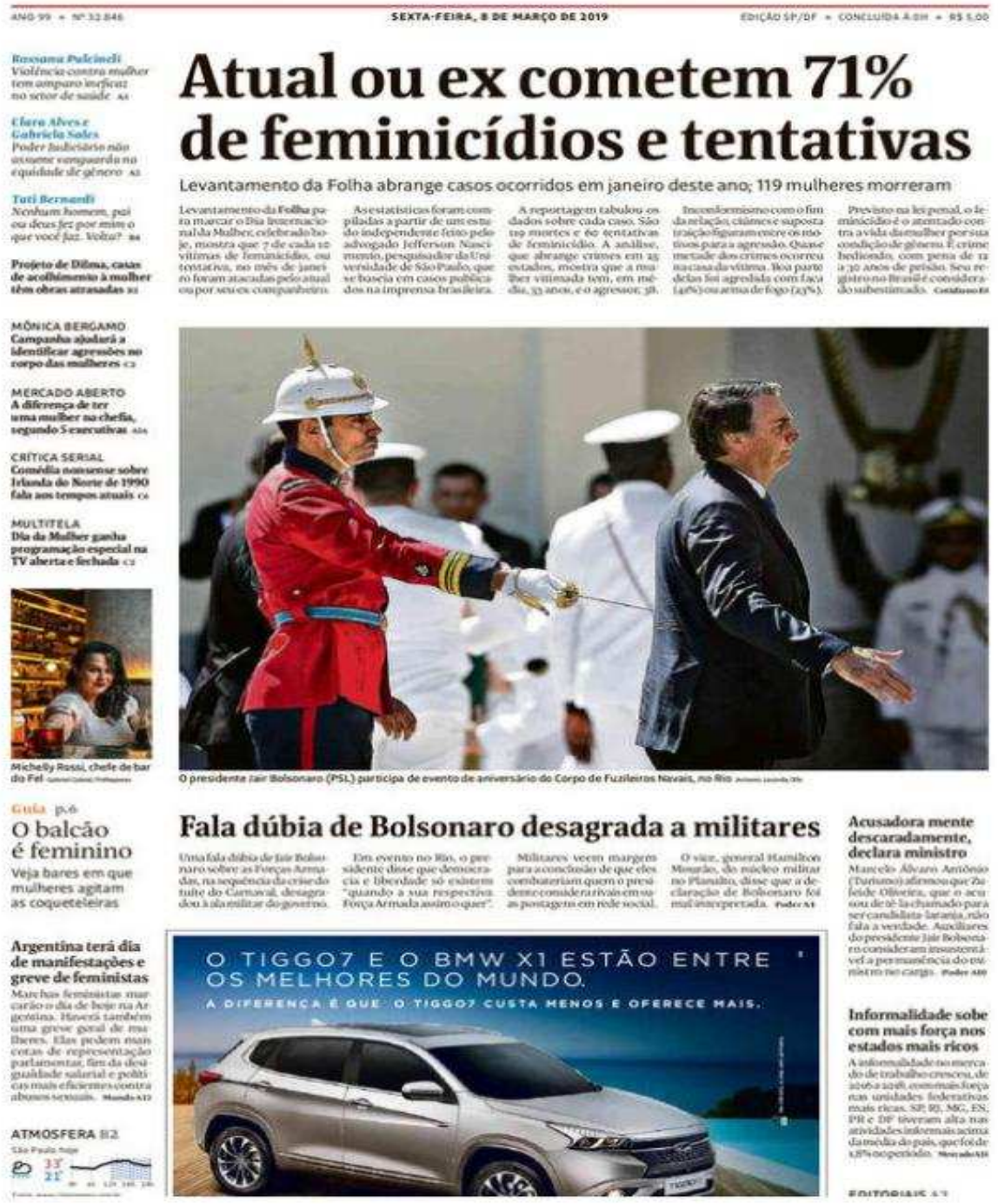




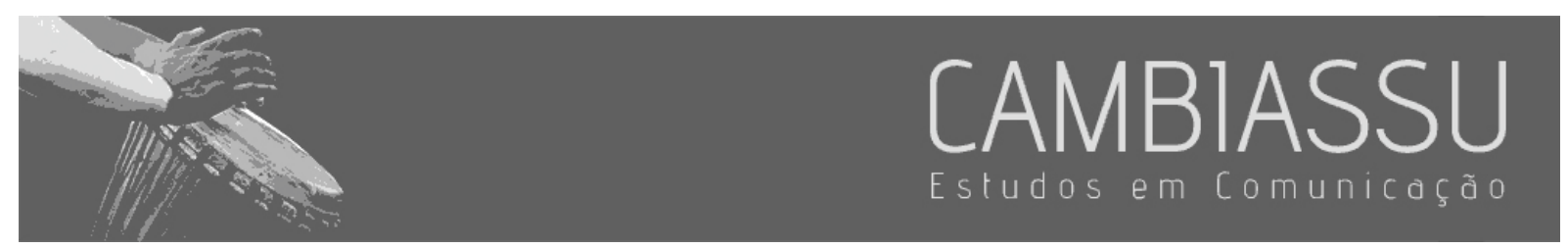

Fonte: Captura de tela realizada pelas autoras/Folha de S. Paulo (2019).

Figura 4 - À esquerda, notícia na capa da Folha de 26 de novembro de 2019

\section{FOLHA DE S.PAULO}

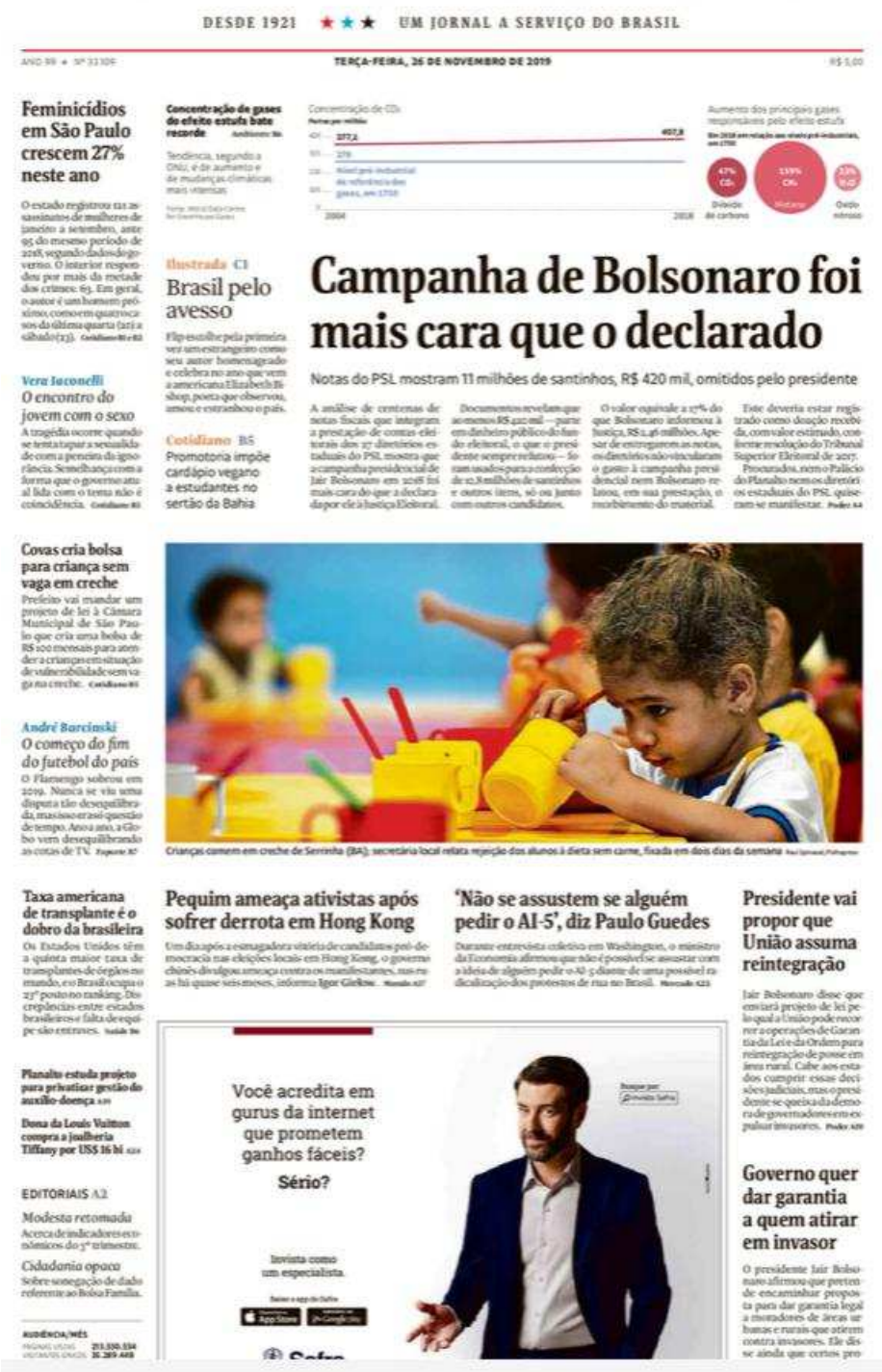

Fonte: Captura de tela realizada pelas autoras/Folha de S. Paulo (2019).

A partir dos aspectos destacados, é possível verificar uma baixa visibilidade conferida a matérias sobre feminicídio em capas da Folha de S. Paulo, exceto em situações de efeméride. Ao mesmo tempo, as matérias localizadas enquadram-se principalmente na editoria de Cotidiano e revelam tratamentos editoriais comuns a outras pautas relacionadas a violência e incidentes policiais, 


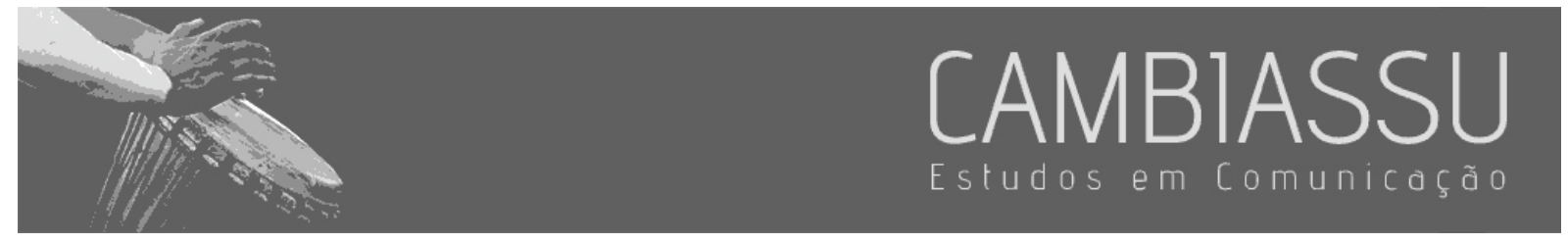

como apontado anteriormente. A seguir, partindo dessa breve descrição dos achados de pesquisa, passaremos à reflexão sobre o que se pode perceber em termos de articulações discursivas presentes nas matérias de capa da Folha sobre feminicídio, bem como o que estes textos revelam em termos de conexão dos enunciados do jornal com discursos em circulação no espaço público.

\section{Articulações discursivas e diálogo com discursos circulantes}

Um aspecto que chama a atenção na cobertura da Folha de S. Paulo sobre casos de feminicídio diz respeito ao predomínio da apuração baseada em dados em todas as notícias analisadas. Além disso, o jornal escutou, nas pautas que constituem nosso corpus, alguns especialistas, militantes contra o feminicídio e fontes oficiais/autoridades.

Em duas matérias - "Atual ou ex cometem $71 \%$ de feminicídios e tentativas", (08/03/2019) e "Em 4 dias, 4 mulheres são mortas por conhecidos em SP" (26/11/2019) -, são citados os nomes das vítimas e assassinos, como aconteceu o crime, o desfecho do caso e, ainda, entrevistas com parentes ou amigos próximos ${ }^{4}$. Assim, as duas notícias em questão destacam-se por englobar tanto dados quanto depoimentos.

No entanto, na maioria das matérias localizadas, as vítimas são apresentadas como números, e não encontramos nomes, depoimentos ou outras formas de humanização recorrentes no jornalismo, recursos estes que poderiam constituir importantes elementos no sentido da construção de um discurso com vistas à sensibilização e conscientização sobre violência de gênero no país.

Em entrevista concedida para a pesquisa a que se refere este artigo, a jornalista da Folha de S. Paulo Júlia Barbon, redatora da matéria "Atual ou ex cometem $71 \%$ de feminicídios e tentativas",

\footnotetext{
${ }^{4}$ Além das duas notícias citadas, há o caso do artigo de opinião intitulado "Um outro final", de 15 de agosto de 2018 , que cita brevemente nomes de mulheres assassinadas. No texto, a referência a nomes de diversas mulheres atua como forma de ilustração, em um efeito retórico/poético, que remente à recorrência desse tipo de crime. Não obstante, as histórias das vítimas não são individualizadas (e, portanto, não são humanizadas: embora tenham nome, elas não são mais do que números).
} 


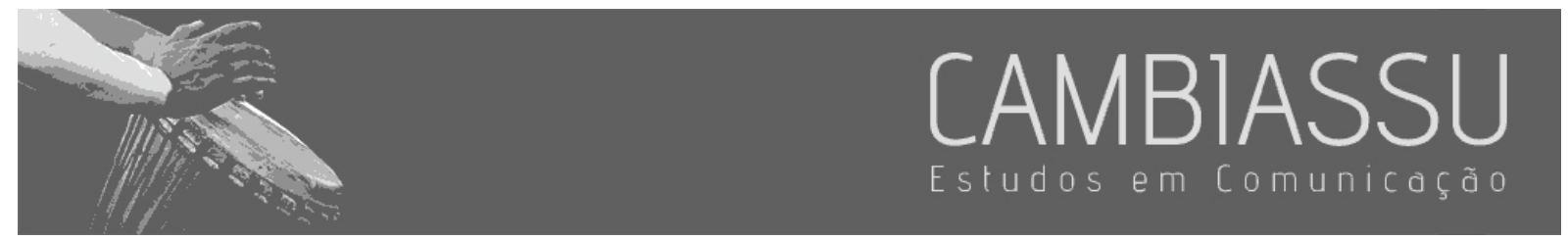

que integra o corpus do presente estudo, explica por que depoimentos de personagens, como familiares e amigos das vítimas, parecem ser incorporados com menor frequência às matérias sobre feminicídio:

A Folha não costuma dar casos isolados de violência, a não ser que seja um caso que tenha muita repercussão. Porque é um jornal nacional e não local que vai dar casos específicos. Então a gente dá quando tem uma visão mais geral de dados. E a Folha adora matéria de dados, é uma coisa mais do estilo do jornal mesmo. Mas especialistas tem muito. Geralmente usamos mais [fontes] para ilustrar. Procuramos um viés mais geral (BARBON, 2020, não paginado) 5 .

A afirmação da jornalista revela um pressuposto interesse, a saber: o de que os muitos casos de feminicídio que acontecem todos os anos no Brasil não recebem atenção individualizada do jornal justamente porque não possuem "muita repercussão". Trata-se de uma percepção indiciária da baixa visibilidade que caracteriza a forma como se percebe, no espaço público, a grande maioria dos casos de feminicídio no Brasil. Ao mesmo tempo, revela um traço importante da forma como o veículo se conecta a discursos circulantes: mais do que se propor a colocar discursos em circulação, o veículo parece assumir para si, ao menos no que diz respeito à cobertura de casos de feminicídio, uma posição reativa em relação a discursos já circulantes no espaço público.

Outro dado relevante que se coloca como ausência significativa nas matérias analisadas diz respeito à invisibilidade da mulher transgênero entre as matérias sobre feminicídio destacadas em capas da Folha. Não houve, em nenhuma das sete capas localizadas, qualquer informação que ilustrasse o feminicídio cometido contra mulheres trans, embora saibamos que se trata de um crime frequente no Brasil. Assim, embora talvez escapasse ao contrato de comunicação da Folha de S. Paulo noticiar casos individuais de feminicídio (inclusive aqueles cometidos contra mulheres trans), esse tipo de crime poderia ser abordado com base em dados que revelam a vulnerabilidade a que estão submetidas essas mulheres no Brasil.

\footnotetext{
${ }^{5}$ A jornalista Júlia Barbon concedeu entrevista para a pesquisa a que se refere este artigo, ocasião em que falou sobre as escolhas editoriais na produção de matérias sobre feminicídio na Folha de S. Paulo. A entrevista foi realizada via chamada de vídeo pelo aplicativo WhatsApp no dia 20 de setembro de 2020.
} 


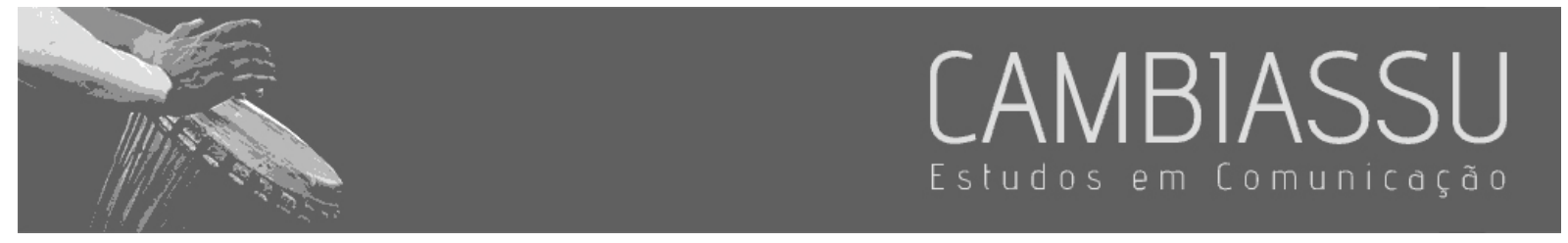

Na contramão da cobertura da Folha, verifica-se que os números relativos a assassinatos de mulheres trans no período coberto pela presente pesquisa são alarmantes:

Segundo o relatório da TGEu, o país registra, em números absolutos, mais que o triplo de assassinatos do segundo colocado, o México, onde foram contabilizadas 256 mortes entre janeiro de 2008 e julho de 2016. Em números relativos, quando se olha o total de assassinatos de trans para cada milhão de habitantes, o Brasil fica em quarto lugar, atrás apenas de Honduras, Guiana e El Salvador (CUNHA, 2020, on-line).

Considerando um intervalo mais recente, observa-se que houve 124 mortes de transexuais e travestis registradas somente em 2019, segundo dados da ANTRA (Associação Nacional de Travestis e Transexuais). Já em 2020, o país liderou o ranking dos países que mais matam por transfobia no mundo, com 175 pessoas assassinadas no período (MINUANO, 2021, on-line).

Ao mesmo tempo, o fato de a maior concentração de matérias na editoria de Cotidiano levar a uma priorização do aspecto episódico do feminicídio parece fazer eco a discursos circulantes ligados à naturalização e banalização desse tipo de violência ou, pelo menos, ao apagamento da especificidade do feminicídio em relação a outros tipos de homicídio, posição que não raro vemos emergir no espaço público, sustentada principalmente por atores sociais que buscam deslegitimar a própria Lei do Feminicídio.

Como assinala Charaudeau (2010), as mídias se conectam aos discursos em circulação pela própria natureza do espaço público, dando-lhes maior ou menor projeção por motivos diversos, que nem sempre envolvem uma intencionalidade clara ou estratégia editorial consciente, mas cujos efeitos de sentido muitas vezes levam ao reforço de concepções presentes no senso comum. Nesse sentido, está em questão, no caso do levantamento apresentado no presente artigo, um modo de conectividade entre jornalismo e opinião pública marcado por uma posição de aquiescência por parte do veículo considerado em relação a discursos circulantes (GOMES; CABRAL, 2011).

Finalmente, cabe observar que a Folha, a partir das ausências que procuramos identificar e descrever ao longo deste trabalho, mostra-se desalinhada em relação às discussões contemporâneas 


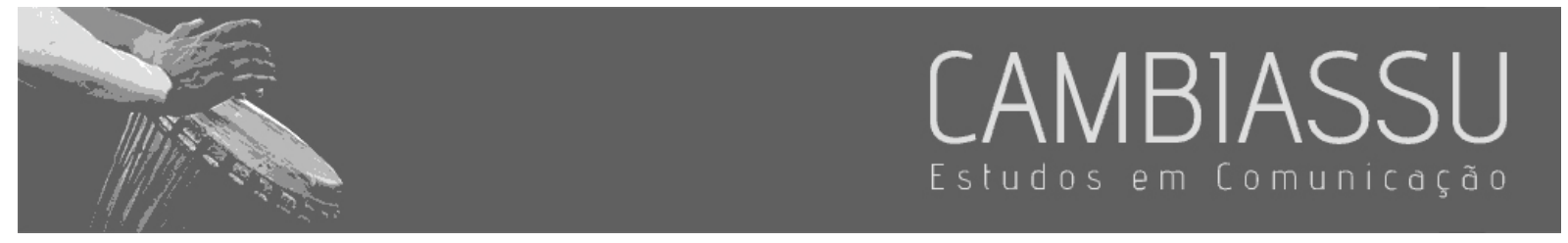

sobre gênero, as quais, emergindo com a terceira e a quarta ondas do feminismo, têm ganhado espaço significativo na cultura midiática, sobretudo em debates conduzidos em redes sociais digitais (HOLLANDA, 2019).

Isso porque o veículo não discute, na cobertura analisada, tópicos como a origem cultural da violência contra a mulher e, tampouco, dá visibilidade às diferenças e desigualdades existentes entre mulheres. Dessa forma, por mais que o veículo pareça empreender esforços, nos últimos anos, no sentido de promover uma cobertura mais consciente em relação às desigualdades de gênero - a exemplo da criação da editoria de Diversidade -, o exame de sua cobertura sobre feminicídio revela o atrelamento de seus enunciados a uma visão ainda essencializada de mulher e uma baixa preocupação em relação ao reconhecimento da existência da interseccionalidade na origem da opressão e violência de gênero.

\section{Considerações finais}

A pouca visibilidade do feminicídio nas capas do jornal, a baixa contextualização dos casos e do debate sobre violência de gênero, o apoio majoritário dos textos em dados com rara humanização, a representação das vítimas como números e a invisibilidade de mulheres trans - todos estes são aspectos que, com base nos achados da pesquisa de que trata o presente artigo, devem ser destacados e problematizados na cobertura da Folha.

Embora o jornalismo, no exercício de sua função cidadã, possa desempenhar um papel significativo na divulgação de informações de qualidade sobre a recorrência de casos de feminicídio e a expressividade desses números no Brasil, o veículo examinado nesta pesquisa concedeu baixa visibilidade, em suas capas, entre 2015 e 2019, a matérias que abordam esse tipo de crime (a única exceção, como vimos, é representada por uma notícia publicada por ocasião do Dia Internacional da Mulher) 


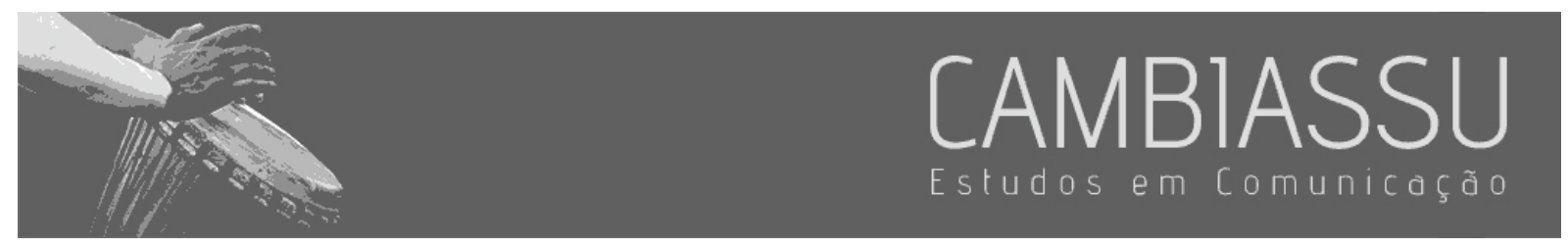

Considerando que a capa de um jornal é um dispositivo de visibilidade, um espaço destinado para notícias que requerem e adquirem notoriedade, a ausência de mais referências a casos de feminicídio neste espaço torna-se um dado significativo em termos da forma como a Folha realiza sua representação/construção do espaço público.

Além disso, como vimos, outras ausências na capa do jornal devem ser consideradas: a exclusão de notícias sobre feminicídios cometidos contra mulheres trans, por exemplo, merece destaque, principalmente tendo em vista os altos números que caracterizam a incidência desse tipo de crime no Brasil durante o período focalizado na pesquisa.

Muitas são as formas pelas quais o discurso midiático se conecta à cultura de uma época e uma sociedade. Assim, considerando que essa cultura se constitui de representações e discursos em circulação, e que ainda hoje o Brasil é um país marcado por uma cultura machista-patriarcal, o silêncio, ainda que parcial, sobre a violência de gênero e o feminicídio também constitui indício de graus variáveis de complacência de um órgão de imprensa em relação a esses discursos.

\section{Referências}

ANTRA. Assassinatos de pessoas trans voltam a subir em 2020. 2020. Disponível em: https://antrabrasil.org/category/violencia/. Acesso em: 15 out. 2020.

BARBOSA, A. MEIRELLES, A. MENEZES, N. Com violência doméstica em alta na pandemia, feminicídios crescem 22\% no país. CNN Brasil. São Paulo, 2020. Disponível em:

https://www.cnnbrasil.com.br/nacional/2020/06/10/com-violencia-domestica-em-alta-na-pandemia-feminicidioscrescem-22-no-pais. Acesso em: 1 jan. 2021.

BARBON, J. Depoimento. [Entrevista concedida a] autora da pesquisa. São Paulo, 2020

COSTA, P. C. Barreiras jornalísticas represam investigações importantes sobre assédio. Folha de S. Paulo. São Paulo, 16 dez. 2018. Disponível em https://www1.folha.uol.com.br/colunas/paula-cesarino-costaombudsman/2018/12/barreiras-jornalisticas-represam-investigacoes-importantes-sobre-assedio.shtml. Acesso em: 25 mar. 2021.

COSTA, P. C. Beijos fora do lugar. Folha de S. Paulo. São Paulo, 18 ago. 2018. Disponível em: https://www1.folha.uol.com.br/colunas/paula-cesarino-costa-ombudsman/2018/08/beijos-fora-do-lugar.shtml. Acesso em: 25 mar. 2021.

CHARAUDEAU, P. Discurso das Mídias. São Paulo: Contexto, 2010.

CUNHA, T. Rotina de exclusão e violência. Correio Braziliense, Brasília. Disponível em: http://especiais.correiobraziliense.com.br/brasil-lidera-ranking-mundial-de-assassinatos-de-transexuais. Acesso em: 23 mar. 2021. 


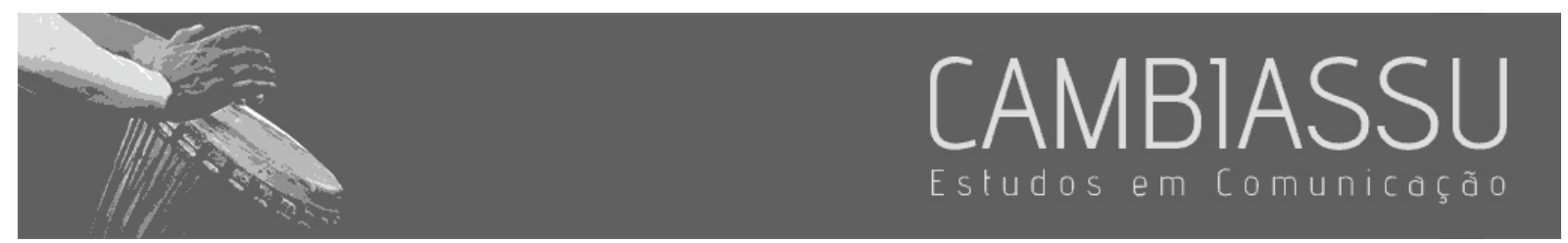

FANTÁSTICO. Exclusivo: número de feminicídios cresce durante pandemia do coronavírus no Brasil. G1. Rio de Janeiro, 31 maio 2020. Disponível em: https://g1.globo.com/fantastico/noticia/2020/05/31/exclusivo-numero-defeminicidios-cresce-durante-pandemia-do-coronavirus-no-brasil.ghtml. Acesso em: 23 mar. 2021.

FLORES, C. de "Razões de Gênero" a "Razões de condição do sexo feminino": Disputas de sentido no processo de criação da lei de feminicídio no Brasil. Seminário Internacional Fazendo Gênero. Florianópolis, jul./ago. 2017. Disponível em:

http://www.en.wwc2017.eventos.dype.com.br/resources/anais/1499450851_ARQUIVO_2017FGClaraFloresversa ofinal.pdf. Acesso em: 9 mar. 2021.

FOLHA de S. Paulo. Atual ou ex cometem $71 \%$ de feminicídios e tentativas. Folha de S. Paulo. São Paulo, 8 mar. 2019. Disponível em: https://www1.folha.uol.com.br/cotidiano/2019/03/71-dos-feminicidios-e-das-tentativastem-parceiro-como-suspeito.shtml. Acesso em: 1 mar. 202.

FOLHA de S. Paulo. Dilma participa da cerimônia sobre a Lei do Feminicídio, no Planalto. Folha de S. Paulo. São Paulo, 9 mar. 2015.

FOLHA de S. Paulo. Mulheres sob ataque. Folha de S. Paulo. São Paulo, 09 mar. 2019. Disponível em: https://www1.folha.uol.com.br/opiniao/2019/03/mulheres-sob-ataque.shtml. Acesso em: 1 mar. 2021. GOMES, P. Violência e tecnologias de gênero: tempo e espaço nos jornais. Revista Estudos Feministas, Florianópolis, v. 17 n. 2, p. 485-505, maio/ago. 2019. Disponível em: https://www.scielo.br/pdf/ref/v17n2/11.pdf. Acesso em: 26 mar. 2021.

GOMES, M. R.; CABRAL, N. L. S. C. Jornalismo: uma relação com opinião pública. Rumores, São Paulo, v. 5, n. 10, p. 1-17, jul./dez. 2011. Disponível em: http://www.rumores.usp.br/pdf/rumores10_1_mayra_nara.pdf. Acesso em: 26 mar. 2021.

HOLLANDA, H. B. (org.). Pensamento feminista: conceitos fundamentais. Rio de Janeiro: Bazar do Tempo, 2019.

LAURETIS, T. de. A tecnologia de gênero. In: HOLLANDA, Heloísa Buarque (org.). Pensamento feminista: conceitos fundamentais. Rio de Janeiro: Bazar do Tempo, 2019, p. 121-155.

MENICUCCI, E. Entenda a lei do feminicídio e por que ela é importante. Guia do Estudante. Disponível em: https://guiadoestudante.abril.com.br/blog/atualidades-vestibular/entenda-a-lei-do-feminicidio-e-por-que-eimportante/. Acesso em: 8 mar. 2021.

MINUANO, C. "Brasil é o país que mais mata pessoas trans; 175 foram assassinadas em 2020". Universa/Uol, 2021. Disponível em: https://www.uol.com.br/universa/noticias/redacao/2021/01/29/brasil-e-o-pais-que-maismata-pessoas-trans-175-foram-assassinadas-em-2020.htm. Acesso em: 29 mar. 2021.

PINTO, C. R. J. Uma história do feminismo no Brasil. São Paulo: Perseu Abramo, 2003.

ZAMIN, A. "Jornalismo de referência: o conceito por trás da expressão". Revista Famecos, Porto Alegre, v. 2, n. 3, p. 918-942, set./dez.2014. Disponível em: https://www.redalyc.org/pdf/4955/495551017008.pdf. Acesso em: 17 Mar. 2021. 